\title{
Synthesis of Vertically Aligned Dense ZnO Nanowires
}

\author{
Lihong Gong, ${ }^{1,2}$ Xiang Wu, ${ }^{2}$ Huibo Chen, ${ }^{2}$ Fengyu Qu, ${ }^{2}$ and Maozhong An ${ }^{1}$ \\ ${ }^{1}$ College of Chemical Engineering and Technology, Harbin Institute of Technology, Harbin 150001, China \\ ${ }^{2}$ College of Chemistry and Chemical Engineering, Harbin Normal University, Harbin 150025, China
}

Correspondence should be addressed to Xiang Wu, wuxiang05@gmail.com and Maozhong An, mzan@hit.edu.cn

Received 1 April 2010; Revised 26 May 2010; Accepted 23 June 2010

Academic Editor: Quanqin Dai

Copyright (C) 2011 Lihong Gong et al. This is an open access article distributed under the Creative Commons Attribution License, which permits unrestricted use, distribution, and reproduction in any medium, provided the original work is properly cited.

\begin{abstract}
We reported the synthesis of vertically aligned dense $\mathrm{ZnO}$ nanowires using $\mathrm{Zn}$ powder as the source material by a hydrothermal method and a postannealing process at $200^{\circ} \mathrm{C}$. The as-synthesized $\mathrm{ZnO}$ nanowires are $100-200 \mathrm{~nm}$ in diameter and several micrometers in length and each nanowire has a tapered tip. The morphologies of the products remain after post-annealing treatment. Structural analysis indicates the $\mathrm{ZnO}$ nanowire is single crystalline and grows along the [0001] direction. The possible growth mechanism for $\mathrm{ZnO}$ nanowire bundles is proposed.
\end{abstract}

\section{Introduction}

Nanostructured materials have been a wide research focus due to their versatile morphologies and excellent physical and chemical properties superior to the corresponding bulk counterparts [1-3]. One-dimensional (1D) nanostructures are investigated not only for their fundamental scientific significance but also for their diverse technological applications in electrical, optical, and sensing fields [4-7]. In general, it is believed that $1 \mathrm{D}$ nanomaterials can show quantum size effect when the sizes are less than the exciton Bohr radius. In view of applications, single nanostructure like nanowire and nanorod should be assembled into devices, in succession integrated into a system. Therefore, recent studies have been inverted into constructing hierarchical and wellaligned 1D nanostructures [8-10]. A lot of efforts have been devoted to synthesize ordered nanostructures, for example, vertically or horizontally aligned nanowire arrays $[11,12]$. The vertically aligned nanowires arrays are in the spotlight owing their conveniences and attractive properties in using as nanodevices, including the nanogenerator [13-15]. 1D nanostructures can be fabricated in various methods, such as vapor deposition [16], laser ablation [17], AAO template plating [18], solution growth [19-21]. Much progress has been made in the growth of $1 \mathrm{D}$ nanostructures, it is still a challenge to assemble well-aligned nanostructures in a rational pathway.
$\mathrm{ZnO}$ is a direct bandgap semiconductor with the band gap energy of $3.37 \mathrm{eV}$ at room temperature and large exciton binding energy of $60 \mathrm{meV}$ [2]. Research of $1 \mathrm{D}$ $\mathrm{ZnO}$ nanostructures can be ascended to the two papers published in the magazine of Science in 2001 [22, 23], from then on the synthesis of $\mathrm{ZnO}$ nanostructures has been a hot issue, splendid morphologies of $\mathrm{ZnO}$ have been synthesized, such as nanonails $[24,25]$, nanorings [26], nanohelices [27], nanowire arrays [28], superlattice structures [29], even hierarchical [30], and hetero-structures [31]. Herein, we reported the synthesis of highly oriented $\mathrm{ZnO}$ nanowire bundles by a two-step process. The growth mechanism of $\mathrm{ZnO}$ nanowire bundles is proposed based on the experimental conditions. The aligned $\mathrm{ZnO}$ bundled nanostructures presented here can be applicable in microand nano-optoelectronic devices.

\section{Experimental Details}

Two grams of zinc powder (Alfa Aesar, $99.99 \%$ purity) was put into $10 \mathrm{ml}$ deionized water and stirred at the room temperature ceaselessly, and then transferred to an autoclave together with a preblended solution, which is obtained by mixing $5 \mathrm{ml} \mathrm{Zn}\left(\mathrm{NO}_{3}\right)_{2}$ solution with $0.5 \mathrm{M}$ concentration and $15 \mathrm{ml} \mathrm{NaOH}$ solution with $5 \mathrm{M}$ concentration. Silicon substrates were also put into the autoclave to collect products. The zinc powder and mixed solution were heated at 


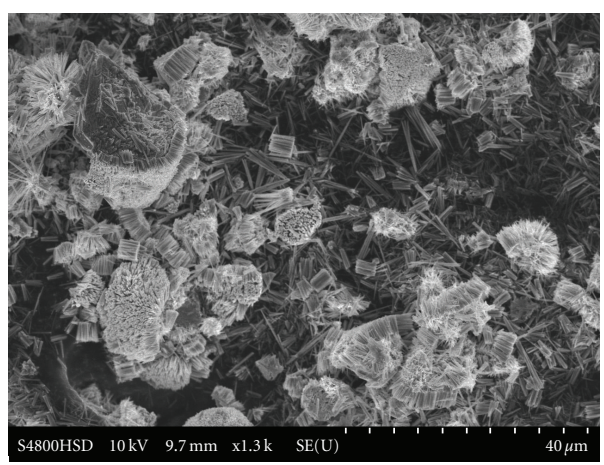

(a)

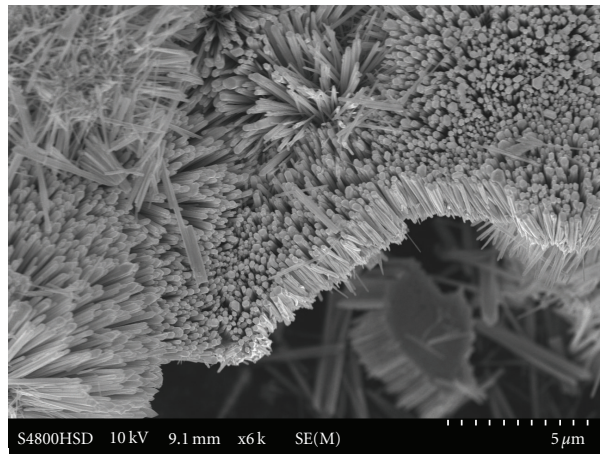

(c)

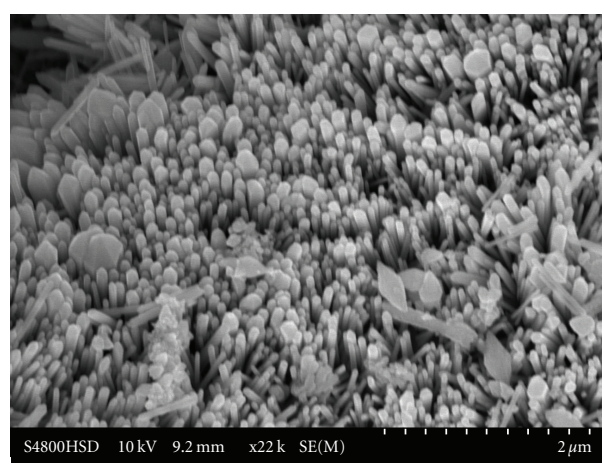

(b)

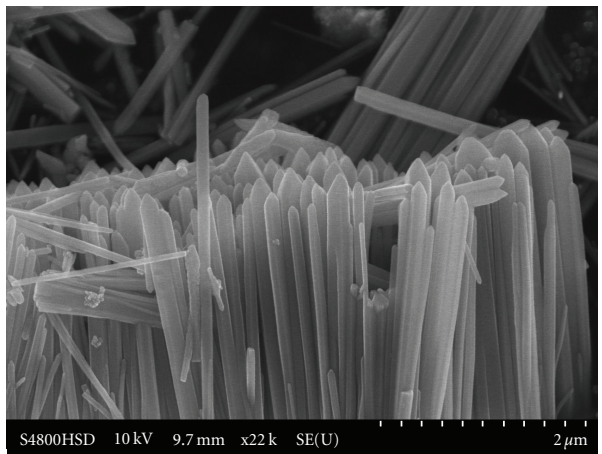

(d)

FIGURE 1: SEM images of as-synthesized products before annealing treatment (a) general low-magnification image (b) a top image, (c) a side image and (d) a local image showing a tapered tip.

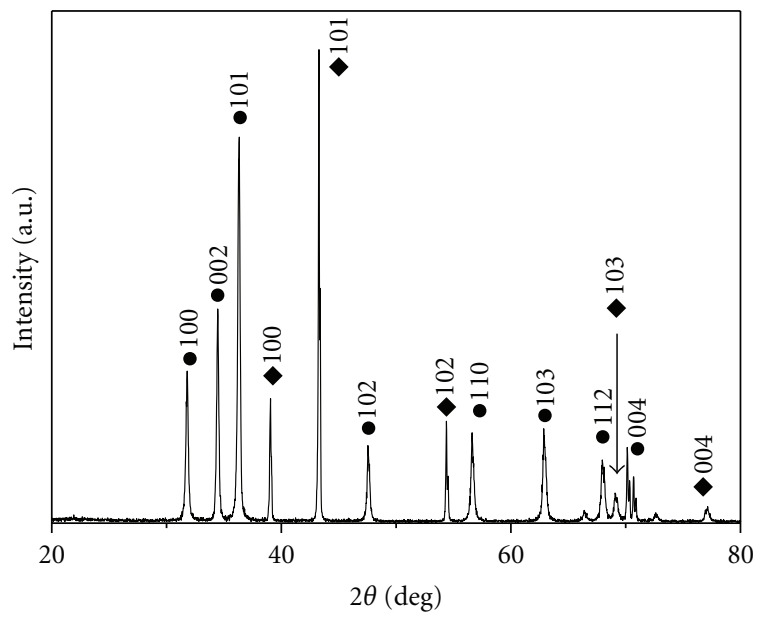

- $\mathrm{ZnO}$

- Zn

FIGURE 2: XRD pattern of as-grown $\mathrm{ZnO}$ nanowires.

$120^{\circ} \mathrm{C}$ for 2 hours and then cooled down. The product was washed using deionized water and ethanol and dried at $200^{\circ} \mathrm{C}$. As-synthesized products were characterized by Xray powder diffraction using $\mathrm{Cu} \mathrm{K} \alpha$ radiation (XRD, Rigaku Dmax-rB, $\lambda=0.1542 \mathrm{~nm}$ ), scanning electron microscope (SEM, Hitachi S-4800), and transmission electron micro-

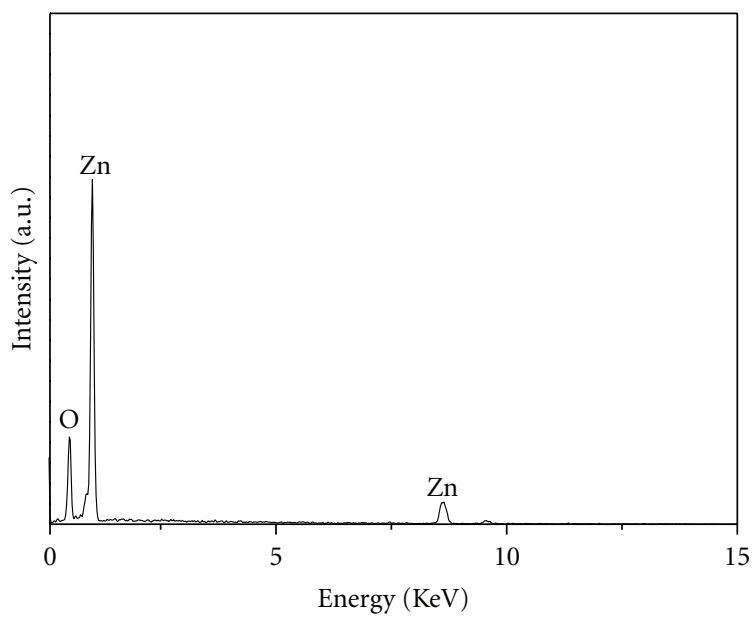

Figure 3: EDS spectrum of as-grown $\mathrm{ZnO}$ nanowires.

scope (TEM, JEOL 2010EX) affiliated with energy dispersive $\mathrm{X}$-ray spectrometer (EDS).

\section{Results and Discussion}

As-synthesized $\mathrm{ZnO}$ nanostructures are shown in Figure 1. The nanowire arrays are found to be vertically aligned in the surfaces of the precursors, similar to the result reported by 


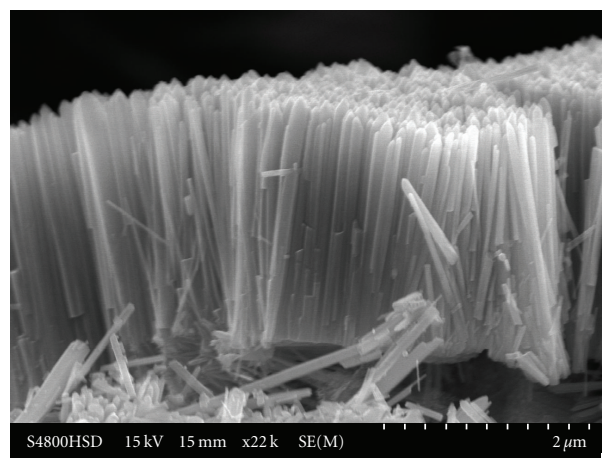

(a)

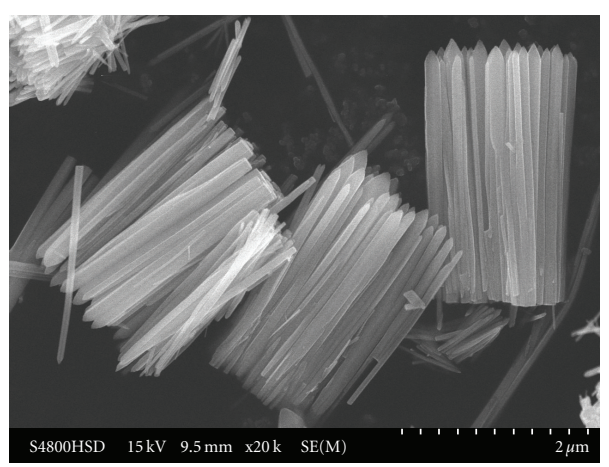

(b)

FIGURE 4: SEM images of as-synthesized products after annealing treatment ((a)-(c)) side images of dense wire bundles; (d) a local image showing several dispersed bundles.

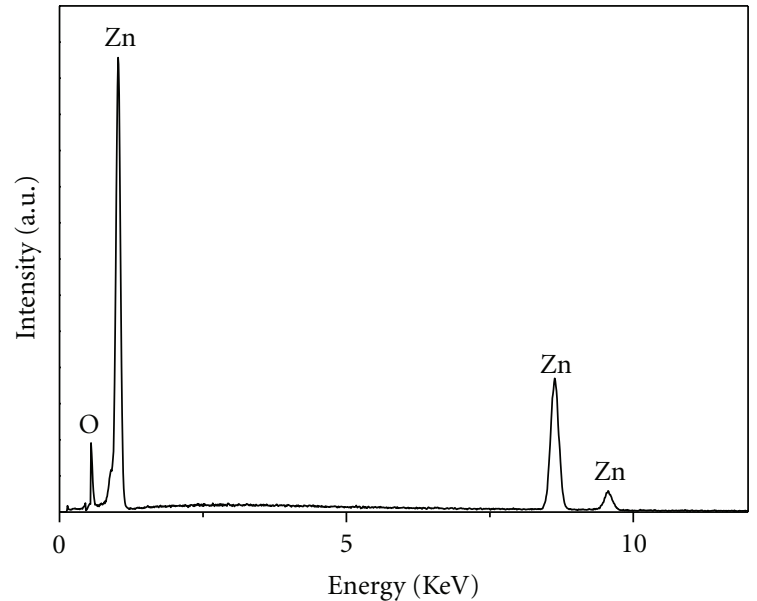

FIGURE 5: EDS spectrum of as-grown $\mathrm{ZnO}$ nanowires after annealing.

$\mathrm{Gu}$ et al. [32], which is realized by a vapor phase process. Each $\mathrm{ZnO}$ nanowires have a tapered tip, a diameter around $200 \mathrm{~nm}$ and a length-diameter ratio of over 10. The XRD spectrum (Figure 2) shows that the as-grown sample is made up of $\mathrm{ZnO}$ and a trace of $\mathrm{Zn}$, without any other phase. This result is consistence with the EDS spectrum, which shows only $\mathrm{Zn}$ and $\mathrm{O}$ (Figure 3). In order to remove the residual $\mathrm{Zn}$, the as-grown samples were annealed at $200^{\circ} \mathrm{C}$ for $2 \mathrm{~h}$. The morphologies still remain (shown in Figure 4) after annealing because $\mathrm{ZnO}$ has a very high melting point of $1975^{\circ} \mathrm{C}$. EDS spectrum of as-obtained product is also presented in Figure 5. TEM is used to study the microstructure of as-grown product. Figure 6(a) is a bright field TEM image of a single nanowire, and the corresponding selected area electron diffraction (SAED) pattern is shown in the inset in Figure 6(a), which indicates that the nanowire are crystalline and grown along the [0001] crystal direction, a common fast growth direction of ZnO. HRTEM image of the $\mathrm{ZnO}$ nanowire showed in Figure 6(b) is consistent with SAED pattern.
$\mathrm{Li}$ et al. synthesized hierarchical $\mathrm{ZnO}$ nanowire arrays at elevated temperatures, and found that $\mathrm{ZnO}$ nanowire arrays were formed by multistep route. Hexagonal disks of $\mathrm{ZnO}$ were firstly formed as basic floor, whose surface may be roughened. $\mathrm{ZnO}$ nanowires were then assembled into a highly oriented array on the top/bottom surfaces of disks in the presence of dense ammonia [33]. Yang et al. synthesized $\mathrm{ZnO}$ nanorod arrays utilizing $\mathrm{Zn}$ foil as $\mathrm{Zn}$ source and water and aqueous ammonia as the solvent at $100^{\circ} \mathrm{C}$, respectively. The as-synthesized nanorods own a smooth tip [34]. Zhang et al. synthesized double tower-tip-like hierarchical $\mathrm{Cu}_{2} \mathrm{O}$ nanostructure. It is thought that the microemulsion system is a prerequisite for the formation of $\mathrm{Cu}_{2} \mathrm{O}$ nanostructures [35]. In this work, $\mathrm{ZnO}$ nanowires array is synthesized at $120^{\circ} \mathrm{C}$ without using ammonia or other organic solution, and the as-synthesized $\mathrm{ZnO}$ nanowires present tapered tips. It means that morphology of as-grown product is relative with not only types and concentration of solvent but also the reaction temperature. Concentration and $\mathrm{pH}$ value of solvent probably also play an important role. A possible growth mechanism of the nanowire bundles we synthesized can be initially proposed as follows: the formation of nanostructure can divided into two step, that is nucleation and growth. $\mathrm{ZnO}$ nucleation occurs at first, $\mathrm{Zn}$ reacts with $\mathrm{OH}^{-}$and forms $\mathrm{ZnO}_{2}{ }^{2-}$ in alkali sodium hydroxide solution. Once the concentration of $\mathrm{ZnO}_{2}{ }^{2-}$ ions reaches saturation $\mathrm{ZnO}_{2}{ }^{2-}$ shall react with $\mathrm{H}_{2} \mathrm{O}$ and induces the nucleation, and subsequent growth of $\mathrm{ZnO}$ nanowire bundles. There is a tapered tip at the top of each nanowire, and it is suggested that sudden perturbation of temperature may lead to formation of tapered tip. Actually reduction of the concentration of reactant is also a factor for growth of nanostructure with tapered tip [36].

\section{Conclusion}

$\mathrm{ZnO}$ nanowire bundles have been synthesized on large scale by a two-step process using $\mathrm{Zn}$ powder as the source. The experimental results indicate the as-synthesized product owns bundle-like morphology in a well-aligned manner. 


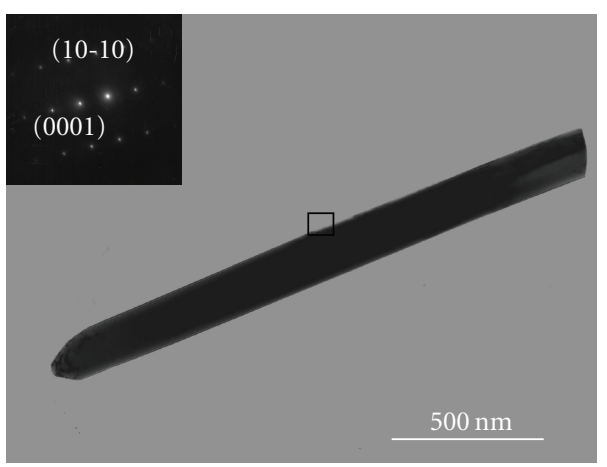

(a)

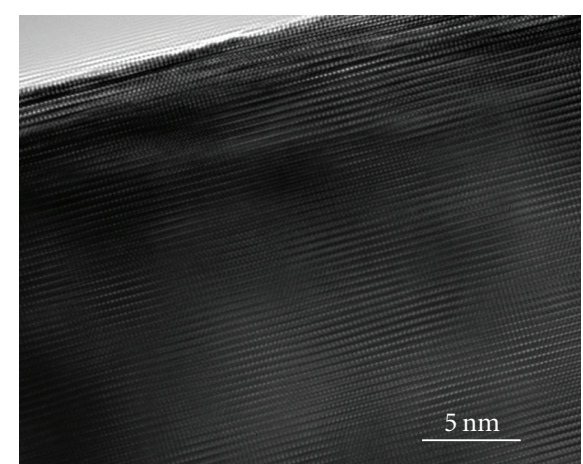

(b)

FIGURE 6: (a) TEM image of as-grown $\mathrm{ZnO}$ nanowires, the inset is the corresponding SAED pattern. (b) HRTEM image taken from the label in Figure 5(a).

Each nanowire forming bundle is $100-200 \mathrm{~nm}$ in diameter and several micrometers in length, and owns a tapered tip. Formation mechanism for nanowire bundles is elucidated based on the reaction conditions. As-grown $\mathrm{ZnO}$ nanowire bundles are expected as ideal functional units for micro/nanodevices. Furthermore, this growth approach can also be used to fabricate nanostructures of other oxide nanostructures.

\section{Acknowledgment}

This paper was supported by the Science Technology and Research Project of Education Bureau, Heilongjiang Province (nos.11551117,11531236)

\section{References}

[1] F. Cheng, J. Zhao, W. Song et al., "Facile controlled synthesis of $\mathrm{MnO} 2$ nanostructures of novel shapes and their application in batteries," Inorganic Chemistry, vol. 45, no. 5, pp. 2038-2044, 2006.

[2] Q. Wan, Q. H. Li, Y. J. Chen et al., "Fabrication and ethanol sensing characteristics of $\mathrm{ZnO}$ nanowire gas sensors," Applied Physics Letters, vol. 84, no. 18, pp. 3654-3656, 2004.

[3] C. Burda, X. Chen, R. Narayanan, and M. A. El-Sayed, "Chemistry and properties of nanocrystals of different shapes," Chemical Reviews, vol. 105, no. 4, pp. 1025-1102, 2005.

[4] H. Chen, X. Wu, L. Gong, C. Ye, F. Qu, and G. Shen, "Hydrothermally grown $\mathrm{ZnO}$ micro/nanotube arrays and their properties," Nanoscale Research Letters, vol. 5, no. 3, pp. 570-575, 2010.

[5] Z. L. Wang and J. Song, "Piezoelectric nanogenerators based on zinc oxide nanowire arrays," Science, vol. 312, no. 5771, pp. 243-246, 2006.

[6] X. Wu, P. Jiang, W. Cai, X.-D. Bai, P. Gao, and S.-S. Xie, "Hierarchical ZnO micro-/nano-structure film," Advanced Engineering Materials, vol. 10, no. 5, pp. 476-481, 2008.

[7] J. Zhou, P. Fei, Y. Gao et al., "Mechanical-electrical triggers and sensors using piezoelectric micowires/nanowires," Nano Letters, vol. 8, no. 9, pp. 2725-2730, 2008.

[8] X. Wu, J. Sui, W. Cai, and F. Qu, "Growth of dendritic $\mathrm{SnO} 2$ nanoarchitectures," Materials Chemistry and Physics, vol. 112, no. 2, pp. 325-328, 2008.
[9] P. Jiang, J.-J. Zhou, H.-F. Fang, C.-Y. Wang, Z. L. Wang, and S.S. Xie, "Hierarchical shelled $\mathrm{ZnO}$ structures made of bunched nanowire arrays," Advanced Functional Materials, vol. 17, no. 8, pp. 1303-1310, 2007.

[10] S. Sun, G. Meng, G. Zhang, J.-P. Masse, and L. Zhang, "Controlled growth of $\mathrm{SnO} 2$ hierarchical nanostructures by a multistep thermal vapor deposition process," Chemistry, vol. 13, no. 32, pp. 9087-9092, 2007.

[11] Z.-J. Li, Z. Qin, Z.-H. Zhou, L.-Y. Zhang, and Y.-F. Zhang, " $\mathrm{SnO} 2$ nanowire arrays and electrical properties synthesized by fast heating a mixture of $\mathrm{SnO} 2$ and CNTs waste soot," Nanoscale Research Letters, vol. 4, no. 12, pp. 1434-1438, 2009.

[12] G. Z. Shen, Y. Bando, J. Q. Hu, and D. Golberg, "Highsymmetry ZnS hepta- and tetrapods composed of assembled ZnS nanowire arrays," Applied Physics Letters, vol. 90, no. 12, Article ID 123101, 2007.

[13] J. Liu, P. Fei, J. Zhou, R. Tummala, and Z. L. Wang, "Toward high output-power nanogenerator," Applied Physics Letters, vol. 92, no. 17, Article ID 173105, 2008.

[14] Y.-F. Lin, J. Song, Y. Ding, S.-Y. Lu, and Z. L. Wang, "Piezoelectric nanogenerator using CdS nanowires," Applied Physics Letters, vol. 92, no. 2, Article ID 022105, 2008.

[15] Z. L. Wang, "Towards self-powered nanosystems: from nanogenerators to nanopiezotronics," Advanced Functional Materials, vol. 18, no. 22, pp. 3553-3567, 2008.

[16] S. Mathur and S. Barth, "Molecule-based chemical vapor growth of aligned $\mathrm{SnO} 2$ nanowires and branched $\mathrm{SnO} 2 / \mathrm{V} 2 \mathrm{O} 5$ heterostructures," Small, vol. 3, no. 12, pp. 2070-2075, 2007.

[17] J. X. Ding, J. A. Zapien, W. W. Chen, Y. Lifshitz, S. T. Lee, and X. M. Meng, "Lasing in $\mathrm{ZnS}$ nanowires grown on anodic aluminum oxide templates," Applied Physics Letters, vol. 85, no. 12, pp. 2361-2363, 2004.

[18] T. Li, S. Yang, and Y. Du, "Strongly luminescent Cr-doped alumina nanofibres," Nanotechnology, vol. 16, no. 4, pp. 365368, 2005.

[19] S.-H. Yu, B. Liu, M.-S. Mo, J.-H. Huang, X.-M. Liu, and Y.-T. Qian, "General synthesis of single-crystal tungstate nanorods/nanowires: a facile, low-temperature solution approach," Advanced Functional Materials, vol. 13, no. 8, pp. 639-647, 2003.

[20] X. P. Gao, Z. F. Zheng, H. Y. Zhu et al., "Rotor-like ZnO by epitaxial growth under hydrothermal conditions," Chemical Communications, no. 12, pp. 1428-1429, 2004. 
[21] Y. J. Chen, X. Y. Xue, Y. G. Wang, and T. H. Wang, "Synthesis and ethanol sensing characteristics of single crystalline $\mathrm{SnO} 2$ nanorods," Applied Physics Letters, vol. 87, no. 23, Article ID 233503, 3 pages, 2005.

[22] Z. W. Pan, Z. R. Dai, and Z. L. Wang, "Nanobelts of semiconducting oxides," Science, vol. 291, no. 5510, pp. 19471949, 2001.

[23] M. H. Huang, S. Mao, H. Feick et al., "Room-temperature ultraviolet nanowire nanolasers," Science, vol. 292, no. 5523, pp. 1897-1899, 2001.

[24] G. Shen, Y. Bando, B. Liu, D. Golberg, and C.-J. Lee, "Characterization and field-emission properties of vertically aligned $\mathrm{ZnO}$ nanonails and nanopencils fabricated by a modified thermal-evaporation process," Advanced Functional Materials, vol. 16, no. 3, pp. 410-416, 2006.

[25] X. Wu, J. Sui, and W. Cai, "Preparation and characterization of semiconductor $\mathrm{ZnO}$ submicron nails," Rare Metal Materials and Engineering, vol. 37, no. 3, pp. 547-550, 2008.

[26] X. Wu, F. Qu, X. Zhang, W. Cai, and G. Shen, "Fabrication of $\mathrm{ZnO}$ ring-like nanostructures at a moderate temperature via a thermal evaporation process," Journal of Alloys and Compounds, vol. 486, no. 1-2, pp. L13-L16, 2009.

[27] X. Wu, W. Cai, and F.-Y. Qu, "Spontaneous formation of single crystal ZnO nanohelices," Chinese Physics B, vol. 18, no. 4, pp. 1669-1673, 2009.

[28] T.-J. Hsueh, S.-J. Chang, Y.-R. Lin, S.-Y. Tsai, I.-C. Chen, and C.-L. Hsu, "A novel method for the formation of ladder-like ZnO nanowires," Crystal Growth and Design, vol. 6, no. 6, pp. 1282-1284, 2006.

[29] P. X. Gao, Y. Ding, W. Mai, W. L. Hughes, C. Lao, and Z. L. Wang, "Materials science: conversion of zinc oxide nanobelts into superlattice-structured nanohelices," Science, vol. 309, no. 5741, pp. 1700-1704, 2005.

[30] F. Xu, K. Yu, Q. Li, Z. Zhu, and T. Yao, "Two-dimensional growth and field emission properties of $\mathrm{ZnO}$ microtowers," Journal of Physical Chemistry C, vol. 111, no. 11, pp. 40994104, 2007.

[31] X. Wu, P. Jiang, Y. Ding, W. Cai, S.-S. Xie, and Z. L. Wang, "Mismatch strain induced formation of $\mathrm{ZnO} / \mathrm{ZnS}$ heterostructured rings," Advanced Materials, vol. 19, no. 17, pp. 2319-2323, 2007.

[32] Z. Gu, M. P. Paranthaman, J. Xu, and Z. W. Pan, "Aligned ZnO nanorod arrays grown directly on zinc foils and zinc spheres by a low-temperature oxidization method," ACS Nano, vol. 3, no. 2, pp. 273-278, 2009.

[33] H. Li, M. Xia, G. Dai et al., "Growth of oriented zinc oxide nanowire array into novel hierarchical structures in aqueous solutions," Journal of Physical Chemistry C, vol. 112, no. 45, pp. 17546-17553, 2008.

[34] H. Yang, Y. Song, L. Li et al., "Large-scale growth of highly oriented $\mathrm{ZnO}$ nanorod arrays in the $\mathrm{Zn}-\mathrm{NH} 3 \cdot \mathrm{H} 2 \mathrm{O}$ hydrothermal system," Crystal Growth and Design, vol. 8, no. 3, pp. 1039-1043, 2008.

[35] H. Zhang, X. Zhang, H. Li, Z. Qu, S. Fan, and M. Ji, "Hierarchical growth of $\mathrm{Cu} 2 \mathrm{O}$ double tower-tip-like nanostructures in water/oil microemulsion," Crystal Growth and Design, vol. 7, no. 4, pp. 820-824, 2007.

[36] G. Z. Wang, Y. Wang, M. Y. Yau, C. Y. To, C. J. Deng, and D. H. L. Ng, "Synthesis of $\mathrm{ZnO}$ hexagonal columnar pins by chemical vapor deposition," Materials Letters, vol. 59, no. 2930, pp. 3870-3875, 2005. 

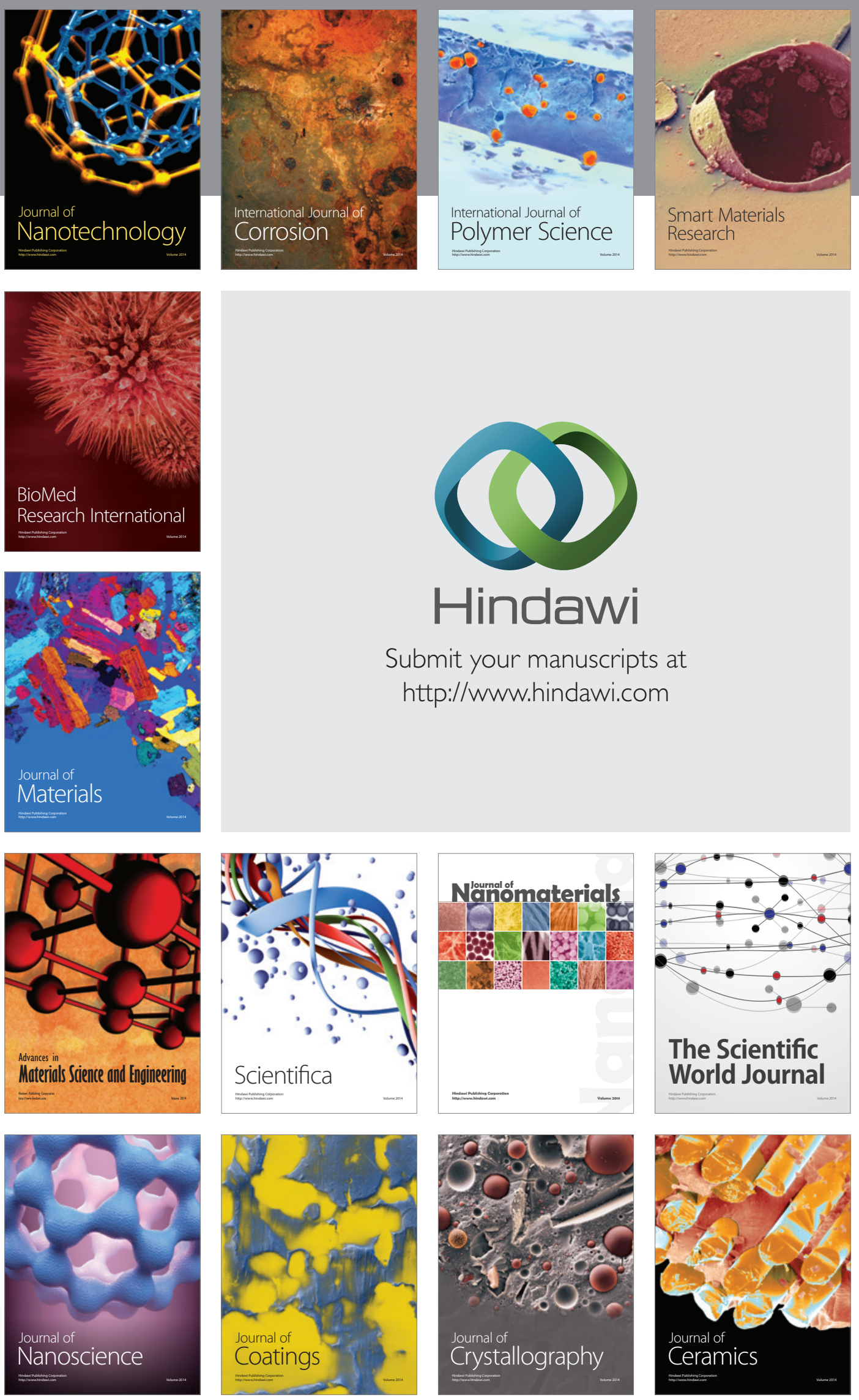

The Scientific World Journal

Submit your manuscripts at

http://www.hindawi.com

\section{World Journal}

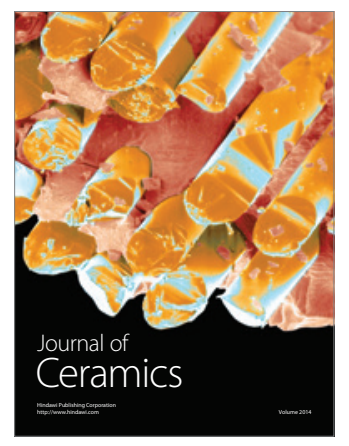

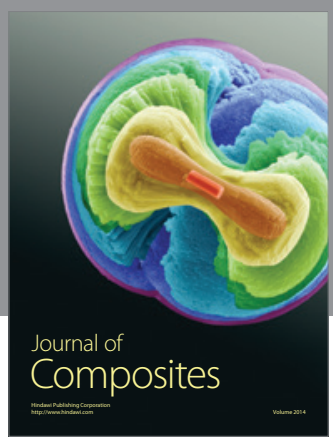
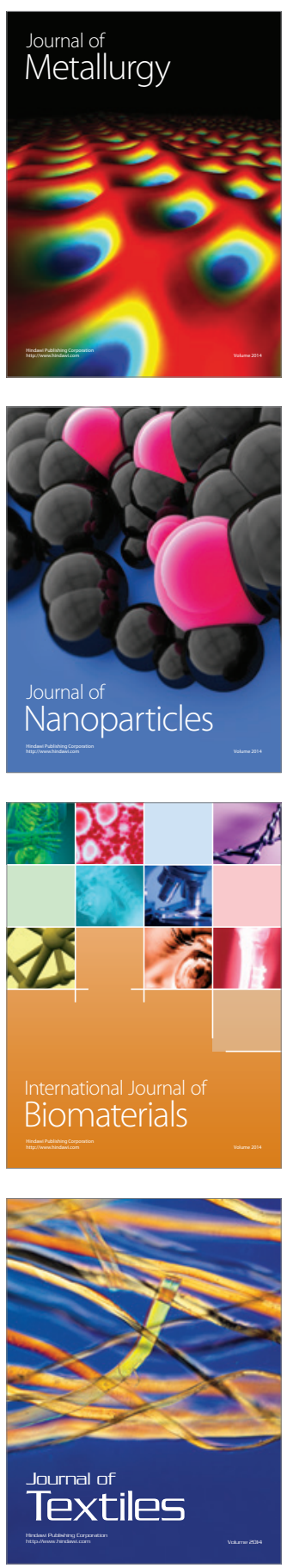